\title{
Early and Progressive Sensorimotor Anomalies in Mice Overexpressing Wild-Type Human $\alpha$-Synuclein
}

\author{
Sheila M. Fleming, ${ }^{1}$ Jonathan Salcedo, ${ }^{1}$ Pierre-Olivier Fernagut, ${ }^{1}$ Edward Rockenstein, ${ }^{3}$ Eliezer Masliah, ${ }^{3}$ \\ Michael S. Levine, ${ }^{2}$ and Marie-Françoise Chesselet ${ }^{1}$ \\ ${ }^{1}$ Departments of Neurology and Neurobiology, ${ }^{2}$ The Mental Retardation Research Center, The David Geffen School of Medicine at University of California \\ Los Angeles, Los Angeles, California 90095-1769, and ${ }^{3}$ Department of Neuroscience, University of California San Diego, La Jolla, California 92093-0624
}

Accumulation of $\alpha$-synuclein in brain is a hallmark of synucleinopathies, neurodegenerative diseases that include Parkinson's disease. Mice overexpressing $\alpha$-synuclein under the Thy-1 promoter (ASO) show abnormal accumulation of $\alpha$-synuclein in cortical and subcortical regions of the brain, including the substantia nigra. We examined the motor deficits in ASO mice with a battery of sensorimotor tests that are sensitive to alterations in the nigrostriatal dopaminergic system. Male wild-type and ASO mice were tested every 2 months for 8 months for motor performance and coordination on a challenging beam, inverted grid, and pole, sensorimotor deficits in an adhesive removal test, spontaneous activity in a cylinder, and gait. Fine motor skills were assessed by the ability to grasp cotton from a bin. ASO mice displayed significant impairments in motor performance and coordination and a reduction in spontaneous activity as early as 2 months of age. Motor performance and coordination impairments became progressively worse with age and sensorimotor deficits appeared at 6 months. Fine motor skills were altered at 4 months and worsened at 8 months. These data indicate that overexpression of $\alpha$-synuclein induced an early and progressive behavioral phenotype that can be detected in multiple tests of sensorimotor function. These behavioral deficits provide a useful way to assess novel drug therapy in genetic models of synucleinopathies.

Key words: basal ganglia; behavior; movement; Parkinson; nigrostriatal; phenotype

\section{Introduction}

The presynaptic protein $\alpha$-synuclein has been implicated in several neurodegenerative diseases and synucleinopathies (Trojanowski and Lee, 2003), including Parkinson's disease (PD), multiple system atrophy, and diffuse Lewy body disease. Abnormal accumulation of $\alpha$-synuclein in the brain is a common feature of these diseases, and this has been modeled in mice by overexpression of wild-type or mutant $\alpha$-synuclein (Fernagut and Chesselet, 2004). Although genetic mouse models of neurodegenerative diseases often do not reproduce the full pathology seen in humans, specific cell loss in particular (Menalled and Chesselet, 2002; Fernagut and Chesselet, 2004), they provide unique tools to test therapies that may interfere with the initial effects of disease-causing mutations and target early stages of the diseases in humans. For this purpose, it is important to use sensitive and reliable measures of behavioral anomalies in these models.

Although excellent sensorimotor tests exist for rats with uni-

Received July 28, 2004; revised Sept. 2, 2004; accepted Sept. 3, 2004.

This work was supported by Morris K. Udall Parkinson's Disease Research Center of Excellence at University of California Los Angeles (P50NS38367) and National Institutes of Health (NIH)-National Institute of Environmental Health Sciences Grants U54ES12078 to M.F.C., AG18440 and AG022074 to E.M., and Training Program in Neural Repair Grant T32 NS07449-05 NIH-National Institute of Neurological Disorders and Stroke (S.M.F., Trainee). We thank Ehud Gruen and Gowry Fernando for their assistance with the mouse colony.

Correspondence should be addressed to Dr. Marie-Françoise Chesselet, Departments of Neurology and Neurobiology, The David Geffen School of Medicine at University of California Los Angeles, 710 Westwood Plaza, Los Angeles, CA 90095-1769. E-mail: mchesselet@mednet.ucla.edu.

DOI:10.1523/JNEUROSCI.3080-04.2004

Copyright $\odot 2004$ Society for Neuroscience $\quad$ 0270-6474/04/249434-07\$15.00/0 lateral nigrostriatal lesions (Schallert and Tillerson, 2000; Schallert et al., 2000; Tillerson et al., 2001, 2002b), it is more difficult to detect anomalies resulting from bilateral dysfunction of the dopaminergic system, particularly in mice. The most common tests used, the rotarod and automated activity monitoring, lack sensitivity to subtle alterations in the nigrostriatal system (Tillerson et al., 2002a; Goldberg et al., 2003). Indeed, previous studies have shown that unless the transgene affects motoneurons, mice overexpressing $\alpha$-synuclein do not show motor alterations until 8-12 months of age (Masliah et al., 2000; Richfield et al., 2002), except for one report of an early decrease in spontaneous rearing that precedes much later alterations on the rotarod (Gispert et al., 2003).

Transgenic mice overexpressing human wild-type $\alpha$-synuclein under the Thy-1 promoter have high levels of $\alpha$-synuclein expression in neurons and $\alpha$-synuclein accumulation in brain, including the substantia nigra but not the spinal cord or neuromuscular junction (Rockenstein et al., 2002). These mice exhibit mitochondrial pathology, axonal degeneration, and perinuclear inclusions in the substantia nigra after subtoxic doses of the neurotoxin 1-methyl-4phenyl-1,2,3,6-tetrahydropyridine (MPTP), suggesting that the overexpression of $\alpha$-synuclein has deleterious effects on nigrostriatal neurons in these mice (Song et al., 2004).

Based on our experience that early and progressive behavioral anomalies can often be detected in genetic models of neurodegenerative diseases when sensitive tests are used (Menalled et al., 2002, 2003; Goldberg et al., 2003), we sought to establish a time course of behavioral deficits in these mice with a battery of novel 
and traditional sensorimotor tasks. Because $\alpha$-synuclein overexpression is known to cause PD in humans (Singleton et al., 2003), we focused on tests sensitive to alterations in the nigrostriatal system. These included tests that reveal deficits in mice with MPTP-induced nigrostriatal degeneration (Tillerson et al., 2002a; Tillerson and Miller, 2003), parkin loss of function (Goldberg et al., 2003), and L-DOPA reversible alterations in a genetic mouse model of nigrostriatal cell loss, the Pitx3-aphakia mouse (Hwang et al., 2003, 2004). Male transgenic $\alpha$-synuclein mice and their wild-type littermates were repeatedly tested between 2 and 8 months of age.

\section{Materials and Methods}

Transgenic mice overexpressing human wild-type $\alpha$-synuclein. Animal care was conducted in accordance with the United States Public Health Service Guide for the Care and Use of Laboratory Animals, and procedures were approved by the University of California Los Angeles Institutional Animal Care and Use Committee. Transgenic mice overexpressing human wild-type $\alpha$-synuclein under the Thy-1 promoter (ASO) were created previously (Rockenstein et al., 2002) and crossed into a mixed C57BL/6-DBA/2 background. Animals were maintained on the mixed C57BL/6-DBA/2 background by breeding mutant females with wild-type males. We found that breeding wild-type females with mutant males produces fewer progeny.

Only male mice were used in the study. In the first experiment, 24 male mice (from a total of six litters), including ASO mice $(n=7)$, and their littermate wild-type controls $(n=17)$ were repeatedly tested at $2,4,6$, and 8 months of age in tests of motor performance and coordination, sensory neglect, and spontaneous activity. Gait was measured at 8 months of age in these mice. Two separate cohorts of male mice were used to measure bin cotton use, a test of fine motor skills, at 4 (ASO, 4; wild type, 4) and 8 (ASO, 4; wild type, 8) months of age. Additional groups of male ASO ( $n=14$ for pole; $n=5$ for inverted grid) and wild-type ( $n=15$ for pole; $n=9$ for inverted grid) mice were tested on the pole and inverted grid tests at 3-4 months of age. The genotype of all ASO and wild-type mice was verified with PCR analysis of tail DNA. Animals were maintained on a $12 \mathrm{hr}$ light/dark cycle with free access to water and food and were group housed with littermates of the same sex (maximum of four per cage).

Body weight. Body weights (in grams) were measured before behavioral testing at 2, 4, 6, and 8 months of age.

Challenging beam traversal (motor performance and coordination). Motor performance was measured with a novel beam test adapted from traditional beam-walking tests (Drucker-Colín and Garcia-Hernandez, 1991; Carter et al., 1999; Dluzen et al., 2001; Goldberg et al., 2003). The beam was constructed from Plexiglas (Plastics Zone, Woodland Hills, CA) and consisted of four sections ( $25 \mathrm{~cm}$ each, $1 \mathrm{~m}$ total length), each section having a different width. The beam started at a width of $3.5 \mathrm{~cm}$ and gradually narrowed to $0.5 \times 1 \mathrm{~cm}$ increments. Underhanging ledges $(1 \mathrm{~cm}$ width) were placed $1.0 \mathrm{~cm}$ below the upper surface of the beam. Animals were trained to traverse the length of the beam starting at the widest section and ending at the narrowest, most difficult section. The narrow end of the beam led directly into the animal's home cage. Animals received $2 \mathrm{~d}$ of training before testing, and all training was performed without the mesh grid. On the first day, animals received two assisted trials, which involved placing the animal on the beam and positioning the home cage in close proximity to the animal. This encouraged forward movement along the beam. After two assisted trials, animals were able to traverse the entire length of the beam unassisted. Day one of training ended after all animals completed five unassisted runs across the entire length of the beam. On day 2 of training, animals were required to run five trials. To increase difficulty further, on the day of the test, a mesh grid ( $1 \mathrm{~cm}$ squares) of corresponding width was placed over the beam surface leaving a $\sim 1 \mathrm{~cm}$ space between the grid and the beam surface. The underhanging ledges provided a support or "crutch" for the animal to use when a limb slipped on the grid (Schallert et al., 2002) and permits assessment of a deficit chronically so that the mice do not need to use compensatory motor strategies to complete the task (Schallert et al.,
2002). Animals were then videotaped while traversing the grid-surfaced beam for a total of five trials.

Videotapes were viewed and rated in slow motion for errors, number of steps made by each animal, and time to traverse across five trials by an investigator blind to the mouse genotype. An error was counted when, during a forward movement, a limb (forelimb or hindlimb) slipped through the grid and was visible between the grid and the beam surface. An individual animal could make a maximum of four slips per step. By scoring each limb slip individually, the severity of the error could be measured. For instance, an animal that slips with three limbs through the grid during a step received an error score of 3, whereas an animal that only slipped one limb through the grid during a step received an error score of 1 for that step. Slips were not counted if the animal was not making a forward movement or when the animal's head was oriented to the left or right of the beam. Error per step scores, time to traverse, and number of steps were calculated for wild-type and ASO mice across all five trials and averaged.

Pole test. The pole test has been used previously to assess basal gangliarelated movement disorders in mice (Ogawa et al., 1985, 1987; Matsuura et al., 1997; Sedelis et al., 2001; Fernagut et al., 2003). Briefly, animals were placed head-up on top of a vertical wooden pole $50 \mathrm{~cm}$ long $(1 \mathrm{~cm}$ in diameter). The base of the pole was placed in the home cage. When placed on the pole, animals orient themselves downward and descend the length of the pole back into their home cage. A separate group of male ASO and wild-type mice (3-4 months of age) received $2 \mathrm{~d}$ of training that consisted of five trials for each session. On the test day, animals received five trials, and time to orient downward ( $\mathrm{t}$-turn) and total time to descend ( $\mathrm{t}$-total) were measured. The best performance over the five trials was used for both wild-type and ASO mice. It has been shown that MPTP-treated mice display slower times in both parameters compared with controls, and the impairments can be reversed by L-DOPA (Ogawa et al., 1985, 1987; Matsuura et al., 1997)

Inverted grid. The inverted grid test was constructed as described previously (Tillerson et al., 2002a; Tillerson and Miller, 2003). Briefly, animals were placed in the center of the inverted grid (mesh, $12 \mathrm{~cm}^{2}$ with 0.5 $\mathrm{cm}^{2}$ squares) $\sim 20 \mathrm{~cm}$ above a table top for $20 \mathrm{sec}$ and videotaped. An observer blind to genotype rated each trial for step distance and forelimb faults per step. It has been shown that moderate doses of MPTP in mice result in shortened forelimb step length and increased forelimb faults per step compared with controls. These parameters are correlated with dopaminergic markers in the striatum and are reversible with L-DOPA (Tillerson et al., 2002a; Tillerson and Miller, 2003).

Adhesive removal. Motor response to sensory stimuli was measured with a stimulation test adapted from rats for mice (Marshall et al., 1971; Marshall and Gotthelf, 1979; Schallert et al., 1982, 1983; Schallert, 1988). Small adhesive stimuli (Avery adhesive-backed labels, one-quarter inch round) were placed on the snout of the mouse, and the time to make contact and remove the stimulus was recorded. To remove the stimulus, animals would raise both forelimbs toward their face and swipe off the stimulus with both forepaws. Typically, wild-type mice make contact and remove the stimulus within $10 \mathrm{sec}$. Each animal received two trials, and the trials were alternated between mice, so that each mouse had an intertrial interval of at least $2 \mathrm{~min}$. All testing was performed in the animal's home cage, and cage mates were temporarily removed during testing because they can interfere with stimulus removal. If the animal did not remove the stimulus within $60 \mathrm{sec}$, the experimenter removed it, and the trial for the next mouse was initiated. Stimulus contact time, removal time, and removal - contact time were calculated for each animal.

Spontaneous activity. Spontaneous movement was measured by placing animals in a small transparent cylinder (height, $15.5 \mathrm{~cm}$; diameter, $12.7 \mathrm{~cm}$ ), which has been used in rat models of Parkinson's disease (Schallert and Tillerson, 2000; Schallert et al., 2000). Spontaneous activity was videotaped for $3 \mathrm{~min}$. In this experiment, the cylinder was placed on a piece of glass and a mirror was situated at an angle beneath the cylinder to permit a clear view of motor movements along the ground as well as along the walls of the cylinder. The number of rears, forelimb and hindlimb steps, and time spent grooming were measured.

Videotapes were viewed and rated in slow motion by an experimenter blind to the mouse genotype. A rear was counted when an animal made 
a vertical movement with both forelimbs removed from the ground. Forelimb and hindlimb steps were counted when an animal moved both forelimbs or both hindlimbs across the floor of the cylinder. Number of steps, rears, and time spent grooming were compared for wild-type and ASO mice at 2, 4, 6, and 8 months of age.

Bin cotton use. Orofacial shredding is an important motor behavior involved in nest building, a natural mouse behavior related to thermoregulation and pup survival (Lynch, 1980; Broida and Svare, 1982; Crawley, 2000). Both male and female mice shred material to build nests, and analysis of shredding behavior has been used to assess nigrostriatal sensorimotor function in rodents (Upchurch and Schallert, 1983; Sedelis et al., 2000; Hofele et al., 2001; Szczypka et al., 2001). The behavior requires the use of orofacial and forelimb movements, where animals pull the nesting material apart with their forelimbs and teeth and then breakdown the material in their mouths and incorporate it into their bedding. To increase the challenge, preweighed cotton was placed into the feeder of the cage in individually housed mice. Pulling the cotton from the feeder requires rearing up in addition to complex fine motor skills. Cotton use was monitored at five time points $(12,24,36,48$, and $72 \mathrm{hr})$ by weighing the remaining cotton in the feeder (bin cotton use). To control for possible alterations in nesting instinct, cotton was placed on the cage floor, and its use was measured over time.

Gait analysis. To measure gait, animals were trained to walk through a narrow alley leading into their home cage. Once trained, paper was placed along the alley floor, and each animal's forelimbs and hindlimbs were brushed with nontoxic paint. Animals were then placed at the beginning of the alley. As they walked into their home cage, they left their paw prints on the paper underneath (Schallert et al., 1978; Barlow et al., 1996; Fernagut et al., 2002; Tillerson et al., 2002a). Stride length was determined by measuring the distance between paw prints. Only strides made while continuously walking (no stopping) were included in the analysis. Stride lengths at the beginning and end of the alley were not counted because animals tend to make irregular steps at the beginning and typically stop and make smaller steps just before entering the cage. Stride width was calculated by measuring the distance between hindlimbs. In addition, the range of stride lengths within each animal was measured by subtracting the shortest stride length from the longest stride length (Dunnett, 2003). Gait was measured in both ASO and wild-type mice at 8 months of age.

Statistics. For motor performance and coordination, a $2 \times 4$ mixed design ANOVA was used to compare mean error per step scores, time to traverse, and number of steps across genotype (between factor) and age (repeated factor). Gender was not taken into account because only male mice were used in the study. For the pole test, ASO and wild-type mice (3-4 months of age) were compared using Mann-Whitney $U$ test. For the inverted grid, Student's $t$ test was used to compare step distance and faults per steps in ASO and wild-type mice. Spontaneous activity was analyzed using a $2 \times 4$ mixed design ANOVA to compare mean number of rears, forelimb and hindlimb steps, and time spent grooming across genotype and age. For adhesive removal, results from the two trials were averaged and group mean removal times and removal-contact time were compared for transgenic and wild-type mice at each age using MannWhitney $U$ test. Bin cotton use was analyzed using $2 \times 5$ mixed design ANOVA to compare genotype and amount of cotton used over time at 4 months of age. Because ASO mice used almost no cotton at 8 months of age, a Mann-Whitney $U$ test was used to compare cotton use at each time. Mean stride length, width, and stride difference were compared for transgenic and wild-type mice with the Student's $t$ test at 8 months of age. Post hoc analysis for the challenging beam and spontaneous activity was done with Fisher's least significant difference (LSD). All analyses were conducted with GB-STAT software (Dynamic Microsystems, Silver Spring, MD) for Macintosh. The level of significance was set at $p<0.05$.

\section{Results}

\section{Body weight}

Wild-type and ASO mice were weighed before behavioral testing at $2,4,6$, and 8 months of age. ANOVA revealed a significant main effect of genotype $F_{(1,22)}=22.95, p<0.01$, a main effect of age $F_{(3,66)}=150.01, p<0.01$, and a significant genotype times

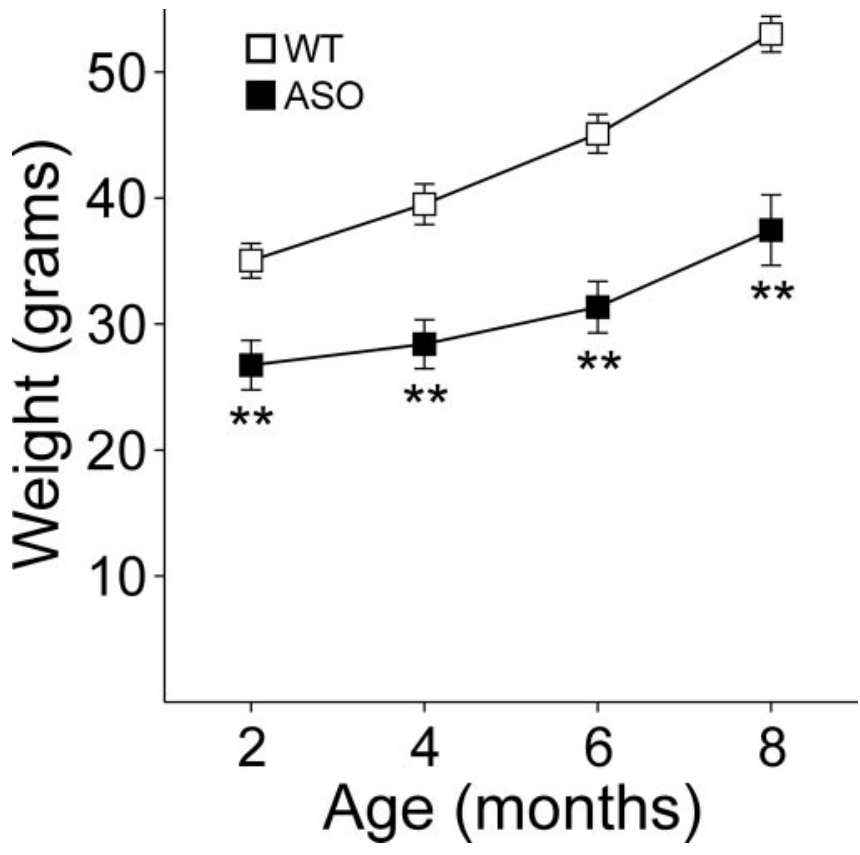

Figure 1. ASO mice were weighed before behavioral testing at 2, 4, 6, and 8 months of age. ASO $(n=7)$ mice weighed significantly less than wild-type $(n=17)$ mice at all ages. Values are expressed as mean weight (in grams) $\pm S E M ;{ }^{* *} p<0.01$ compared with wild type.

age interaction $F_{(3,66)}=5.11, p<0.01$. ASO mice weighed significantly less than wild-type mice at each age tested $(p<0.01)$. Both wild-type and ASO mice gained weight as they aged (Fig. 1).

\section{Challenging beam traversal}

ASO and littermate wild-type control mice were tested for motor performance and coordination on the beam traversal test. Errors per step, steps, and time to traverse were recorded for each animal. For errors per step, ANOVA indicated a significant effect of genotype $F_{(1,22)}=156.17, p<0.01$, a significant effect of age $F_{(3,66)}=32.92, p<0.01$, and a significant genotype by age interaction $F_{(3,66)}=20.47, p<0.01$. Post hoc analysis with Fisher's LSD indicated that ASO animals made significantly more errors compared with wild-type controls at each age $(p<0.01)$. At 6 and 8 months of age, ASO mice became progressively worse compared with their performance at the younger ages $(p<0.01)$. Similarly, ANOVA comparing the number of steps across genotype and age revealed a significant main effect of genotype $F_{(1,22)}=6.68, p<0.05$, and a significant effect of age $F_{(3,66)}=$ $6.74, p<0.01$. Post hoc analysis indicated that ASO mice made significantly more steps while traversing the beam compared with wild-type controls at 2 and 8 months of age $(p<0.01)$. In addition, ASO animals at 8 months of age made even more steps compared with their performance at younger ages $(p<0.01)$. For time to traverse, ANOVA revealed a significant effect of genotype $F_{(1,22)}=19.86, p<0.01$, and a significant effect of age $F_{(3,66)}=4.17, p<0.01$. Post hoc analysis indicated that ASO animals took significantly longer to traverse the beam compared with wild-type mice ( $p<0.05$ for 2,4 , and 6 months; $p<0.01$ for 8 months). In addition, ASO mice at 8 months of age took even longer to traverse compared with their performance at $2(p<$ $0.01), 4(p<0.05)$, and $6(p<0.01)$ months (Fig. 2).

\section{Pole test}

Time to orient down (t-turn) and total time to descend the pole (t-total) were measured for a separate group of male ASO $(n=$ 


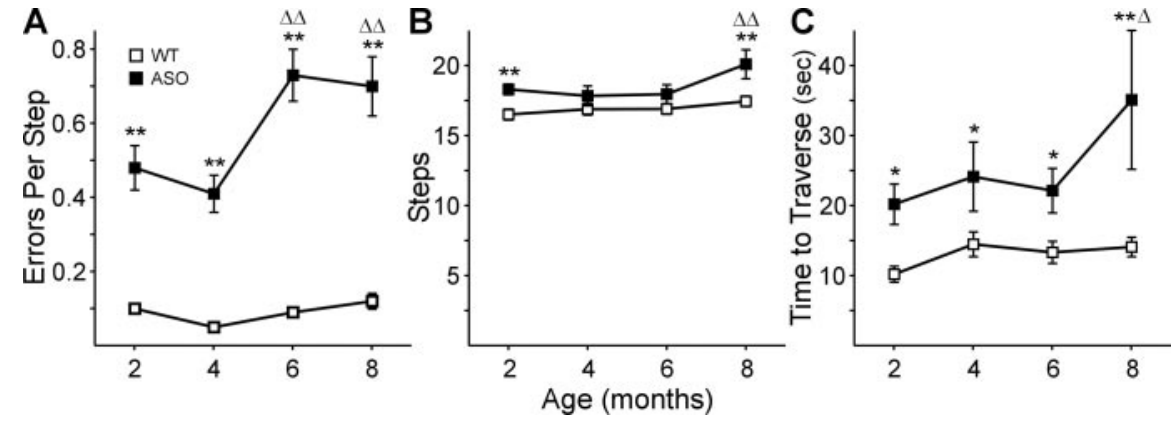

Figure 2. Motor performance and coordination was measured in ASO $(n=7)$ and wild-type $(n=17)$ mice using the challenging beam. Errors per step $(A)$, number of steps $(B)$, and time to traverse $(C)$ were measured at $2,4,6$, and 8 months of age. ASO mice made more errors and steps and took longer to traverse the beam compared with wild-type mice. In addition, ASO impairments worsened over time. Values are expressed as mean \pm SEM. ${ }^{*} p<0.05$ and ${ }^{* *} p<0.01$, compared with wild-type mice at the same age; ${ }^{\Delta \Delta} p<0.01$, compared with previous ages tested within the ASO group.

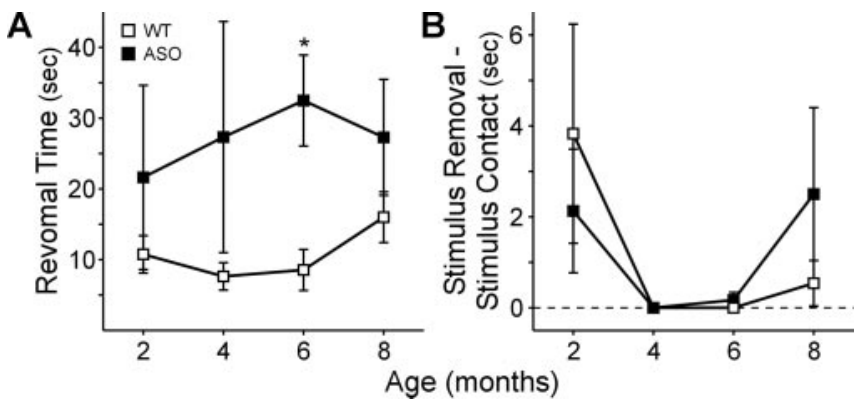

Figure 3. Adhesive removal was measured in $\mathrm{ASO}(n=7)$ and wild-type $(n=17)$ mice at 2 , 4,6 , and 8 months of age. At 6 months of age, ASO mice were significantly slower to respond to sensory stimuli compared with wild-type mice $(A)$. The time from stimulus contact to stimulus removal did not differ between ASO and wild-type mice $(B)$. Values are expressed as means \pm SEM. * $p<0.05$, compared with wild-type mice.

$14)$ and wild-type $(n=15)$ mice at $3-4$ months of age. Mean scores (in seconds) for t-turn were $2.24 \pm 0.53$ for wild-type mice and $37.42 \pm 7.33$ for ASO mice. For t-total, wild-type mice took $7.06 \pm 1.23 \mathrm{sec}$ and ASO mice took $73.51 \pm 14.93 \mathrm{sec}$ to descend the pole. Mann-Whitney $U$ test indicated that ASO mice showed robust impairments in the pole test. ASO mice took significantly longer to turn and descend down the pole compared with wildtype mice $(p<0.01)$.

\section{Inverted grid}

Step distance and forelimb faults per step were measured for a separate group of male ASO $(n=5)$ and wild-type $(n=9)$ mice at 3-4 months of age. Mean step distance scores (number of squares crossed during a step) were $4.53 \pm 0.30$ for wild-type mice and $3.36 \pm 0.30$ for ASO mice. Mean faulting scores were $0.10 \pm 0.01$ for wild-type and $0.24 \pm 0.07$ for ASO mice. Student's $t$ test revealed a significant decrease in step distance in ASO compared with wild-type mice $(p<0.05)$. Although faulting scores were higher in ASO mice, this difference did not reach statistical significance $(p>0.05)$.

\section{Adhesive removal}

Time to respond and make contact with sensory stimuli was recorded in each mouse. Analysis with Mann-Whitney $U$ test indicated that at 6 months of age, ASO mice took significantly longer to make contact and remove the stimulus compared with wildtype mice $(p<0.05)$. Although response times were not significantly different at the other ages tested, mean removal times were higher for ASO animals compared with wild-type mice at all ages. Adhesive removal-contact time scores were not significantly different between ASO and wild-type mice ( $p>0.05)$ (Fig. 3).

\section{Spontaneous activity}

Spontaneous rearing, forelimb and hindlimb steps, and grooming were measured for $3 \mathrm{~min}$. For rearing, ANOVA revealed a significant effect of age $F_{(3,66)}=12.42, p<$ 0.01 . Post hoc analysis indicated that at 2 months of age, ASO animals reared significantly less compared with wild-type mice $(p<0.05)$. For forelimb stepping, ANOVA indicated a main effect of age $F_{(3}$, 66) $=6.58, p<0.01$. Post hoc analysis showed a significant reduction in the number of forelimb steps made by ASO mice compared with wild-type mice at 2 and 6 months $(p<0.05)$. For hindlimb stepping, ANOVA revealed a main effect of genotype $F_{(1,22)}=$ $10.74, p<0.01$, a main effect of age $F_{(3,66)}=35.81, p<0.01$, and a significant genotype times age interaction $F_{(3,66)}=4.80, p<$ 0.01 . Fisher's LSD indicated that at all ages tested, ASO mice made significantly fewer hindlimb steps compared with wildtype mice $(p<0.01)$. For grooming, ANOVA indicated a main effect of genotype $F_{(1,22)}=4.53, p<0.05$. Fisher's LSD revealed that ASO mice groom significantly less than wild-type mice at 8 months of age $(p<0.05)$ (Fig. 4$)$.

\section{Bin cotton use}

Fine motor skill was measured in separate groups of 4-month old $(n=8)$ and 8 -month-old $(n=12)$ ASO and wild-type mice by assessing the ability of the mice to grasp cotton for nest building from the cage bin. For the 4-month-old mice, ANOVA revealed a main effect of time $F_{(4,24)}=2.89(p<0.05)$. Post hoc analysis indicated that ASO mice used significantly less cotton compared with wild-type mice at all time points $(p<0.01)$. For 8 -monthold mice, Mann-Whitney $U$ test indicated that ASO mice used significantly less cotton compared with wild-type mice at each time point $(p<0.01)$. Because the 8 -month-old ASO mice did not use the cotton in the feeder, an additional experiment was performed to assess whether they can build nests at all. Preweighed cotton was placed on the cage floor, and cotton use was measured for each animal at 24, 48, and $72 \mathrm{hr}$. In this experiment, wild-type mice used all of the cotton within $24 \mathrm{hr}$, whereas ASO mice used all of their cotton by $72 \mathrm{hr}$. Thus, ASO mice do have the nesting instinct and are able to shred cotton. However, ASO animals did show a delay in cotton use when the cotton was placed in the cage, indicating that motivation to build a nest could be impaired (Fig. 5).

\section{Gait analysis}

Stride length, width, and stride difference were measured for both ASO and wild-type mice. ASO mice did not significantly differ from wild-type mice in stride length, width, or stride difference (the difference between the longest and shortest strides), although there was a trend for ASO animals to have more variable stride lengths ( $p=0.09$; NS). Thus, despite a shortening of stride lengths on the challenging beam with recessed platform below and on the inverted grid, there was only a trend for smaller steps $(p>0.05)$. 


\section{Discussion}

Several transgenic mice overexpressing $\alpha$-synuclein, a model of synucleinopathies, have been generated (Fernagut and Chesselet, 2004). However, finding early behavioral anomalies in these mice has proven challenging, except for models with motoneuron degeneration, which is not a common feature of synucleinopathies in humans (van der Putten et al., 2000). We show that mice overexpressing human $\alpha$-synuclein under the Thy-1 promoter display robust sensorimotor impairments in several behavioral measures at an early age. Although the mechanisms leading to these motor impairments remain unknown, they occur in mice with pathological accumulation of $\alpha$-synuclein in cortical and subcortical regions, including the substantia nigra pars compacta (Rockenstein et al., 2002). Importantly, these mice do not have abnormal $\alpha$-synuclein accumulation in the spinal cord, neuromuscular junction, or in glial cells (Rockenstein et al., 2002), suggesting that their sensorimotor deficits are attributable to alterations in brain neurons.

\section{ASO mice exhibit an early and progressive behavioral phenotype}

We were able to detect sensorimotor impairments as early as 2 months of age in several sensitive behavioral tests. At 2 months of age, ASO mice displayed significant deficits in all parameters of the challenging beam, including errors, time to traverse, and number of steps. The impairments in the first two parameters persisted throughout the course of the study. ASO mice were also impaired in the inverted grid and pole tests, two additional tests of motor coordination. ASO animals became worse on the challenging beam beginning at 6 months, indicating that the motor deficit was progressive. Motor performance was also altered in another $\alpha$-synuclein overexpressing mouse, although the age of onset of these deficits was not specified (Gispert et al., 2003).

ASO mice also showed a deficit in their response to sensory stimuli. At 6 months of age, ASO mice were slower to respond to sensory stimuli compared with wild-type mice. Because the time from first contact until the time to remove the stimulus was not different between ASO and wild-type mice, the impairment in stimulus removal is likely attributable to a motor impairment rather than a lack of motivation to remove the stimulus. In addition to motor performance and stimulus removal deficits, ASO mice showed impairments in several spontaneous movements measured within the confine of a cylinder. Similar to a previous report (Gispert et al., 2003), ASO mice showed decreased rearing at an early age. However, although all measured parameters were lower at some time points in ASO than in wild-type mice, only hindlimb stepping was significantly decreased at all the ages tested. When viewed on the video, ASO mice hardly moved their hindlimbs while moving their upper body in a manner similar to wild-type mice.

A general concern with many activity and performance tests is that stress can affect, and possibly mask, sensorimotor deficits. To address this issue, we also used a nest-building task that tested the ability of mice to grasp cotton through the cage bin, shred it, and build a nest. The task relies on a natural instinct for both male and female mice and takes place in the home cage, without any intrusion from the investigator. Similar to the challenging beam, ASO mice showed a major, progressive deficit in bin cotton use. By 8 months of age, ASO mice used virtually no cotton from the bin. A lack of nesting instinct does not explain the results because ASO mice did build nests, although less proficiently than wild-type mice, when cotton was placed in the cage. It is likely that ASO mice have impairment in fine motor skills; however, we cannot exclude the possibility that they could have a reduction in the shredding urge without a loss of the nesting instinct. The latter case may involve dysfunction within the cortex in addition to the nigrostriatal system (Kolb and Whishaw, 1985). ASO mice have high levels of expression of $\alpha$-synuclein within the neocortex, and cortical dysfunction could contribute to the observed impairments in bin cotton use (Rockenstein et al., 2002).

\section{Role of the nigrostriatal system in sensorimotor deficits in ASO mice}

Because ASO mice overexpress normal human $\alpha$-synuclein, which in humans causes early onset familial PD (Singleton et al., 2003), we focused on tests sensitive to dopaminergic dysfunction, a hallmark of PD (Upchurch and Schallert, 1983; Ogawa et al., 1985, 1987; Matsuura et al., 1997; Sedelis et al., 2000; Hofele et al., 2001; Szczypka et al., 2001; Tillerson and Miller, 2003). We have shown previously that mice with a loss of dopaminergic neurons caused by a defect in Pitx3 show similar alterations to ASO mice in several of these tests, and in most cases these alterations are reversed by L-DOPA (Hwang et al., 2003, 2004). The ASO mice do not exhibit a loss of dopaminergic neurons but develop accumulation of $\alpha$-synuclein in brain, including the nigrostriatal system, and show enhanced sensitivity of nigrostriatal neurons to 
the neurotoxin MPTP (Rockenstein et al., 2002; Song et al., 2004). Furthermore, in vitro evidence links $\alpha$-synuclein overexpression to alterations in DA release and synthesis (Lotharius and Brundin, 2002; Lotharius et al., 2002; Perez et al., 2002). Therefore, behavioral deficits in ASO could be attributable to dopaminergic dysfunction, even in the absence of cell loss. In addition to the nigrostriatal system, however, $\alpha$-synuclein overexpression is likely to affect a variety of brain regions in ASO, as suggested by their widespread neuropathological anomalies (Rockenstein et al., 2002). Differences in behavioral phenotypes between Pitx3 - / - mice and ASO also support a role for other neuronal pathways in addition to the nigrostriatal system (Hwang et al., 2004).

\section{ASO and synucleinopathies}

Synucleinopathies are a group of diseases linked by the abnormal accumulation of $\alpha$-synuclein in various cells and brain regions, depending on the specific disease (Trojanowski and Lee, 2003). The pattern of $\alpha$-synuclein overexpression and accumulation in ASO mice resembles aspects of PD (Rockenstein et al., 2002). Indeed, $\alpha$-synuclein pathology is also widespread in the brain in PD (Braak et al., 2003). Recent pathological studies have challenged the long-held belief that loss of dopaminergic neurons is the first manifestation of the disease. In sporadic PD, $\alpha$-synuclein pathology may develop in the medulla, olfactory bulb, and locus ceruleus before the nigrostriatal dopaminergic neurons (Braak et al., 2003).

The clinical equivalent of the sensorimotor anomalies we observed in the ASO is unclear. Whatever their equivalent in humans, the behavioral deficits in ASO mice offer a functional correlate to the pathological accumulation of $\alpha$-synuclein in brain neurons. A major advance provided by the identification of molecular mechanisms in neurodegenerative diseases is the possibility to target new therapies to the mechanisms rather than the symptoms of the disease. It is particularly important to test these therapies before cell loss occurs. Most neurodegenerative diseases include a "presymptomatic" phase spanning the time from disease inception until the manifestation of cardinal symptoms that lead to their diagnosis, during which patients may exhibit more subtle, undiagnosed anomalies (Langston and Koller, 1991; Lees, 1992; Przuntek, 1992; Di Paola and Uitti, 1996; Rossini et al., 1998; Brooks et al., 2003). This presymptomatic phase may present a window of opportunity to begin neuroprotective treatments. Early and progressive motor impairments, as described here in ASO mice, are critical for testing potential treatments early in disease progression.

\section{References}

Barlow C, Hirotsune S, Paylor R, Liyanage M, Eckhaus M, Collins F, Shiloh Y, Crawley JN, Ried T, Tagle D, Wynshaw-Boris A (1996) Atm-deficient mice: a paradigm of ataxia telangiectasia. Cell 86:159-171.

Braak H, Del Tredici K, Rub U, de Vos RA, Jansen Steur EN, Braak E (2003) Staging of brain pathology related to sporadic Parkinson's disease. Neurobiol Aging 24:197-211.

Broida J, Svare B (1982) Strain-typical patterns of pregnancy-induced nestbuilding in mice: maternal and experiential influences. Physiol Behav 29:53-57.

Brooks DJ, Frey KA, Marek KL, Oakes D, Paty D, Prentice R, Shults CW, Stoessl AJ (2003) Assessment of neuroimaging techniques as biomarkers of the progression of Parkinson's disease. Exp Neurol 184[Suppl $1]: 68-79$.

Carter RJ, Lione LA, Humby T, Mangiarini L, Mahal A, Bates GP, Dunnett SB, Morton AJ (1999) Characterization of progressive motor deficits in mice transgenic for the human Huntington's disease mutation. J Neurosci 19:3248-3257.
Crawley JN (2000) What's wrong with my mouse? Behavioral phenotyping of transgenic and knockout mice, pp 151-165. New York: Wiley.

Di Paola R, Uitti RJ (1996) Early detection of Parkinson's disease. Implications for treatment. Drugs Aging 9:159-168.

Dluzen DE, Gao X, Story GM, Anderson LI, Kucera J, Walro JM (2001) Evaluation of nigrostriatal dopaminergic function in adult $+/+$ and $+/-$ BDNF mutant mice. Exp Neurol 170:121-128.

Drucker-Colín R, Garcia-Hernandez F (1991) A new motor test sensitive to aging and dopaminergic function. J Neurosci Methods 39:153-161.

Dunnett SB (2003) Assessment of motor impairments in transgenic mice. In: Mouse behavioral phenotyping (Crawley JN, ed), pp 1-12. Washington, DC: Society for Neuroscience.

Fernagut P-O, Chesselet M-F (2004) Alpha-synuclein and transgenic mouse models. Neurobiol Dis, in press.

Fernagut PO, Diguet E, Labattu B, Tison F (2002) A simple method to measure stride length as an index of nigrostriatal dysfunction in mice. J Neurosci Methods 113:123-130.

Fernagut PO, Chalon S, Diguet E, Guilloteau D, Tison F, Jaber M (2003) Motor behaviour deficits and their histopathological and functional correlates in the nigrostriatal system of dopamine transporter knockout mice. Neuroscience 116:1123-1130.

Gispert S, Del Turco D, Garrett L, Chen A, Bernard DJ, Hamm-Clement J, Korf HW, Deller T, Braak H, Auburger G, Nussbaum RL (2003) Transgenic mice expressing mutant A53T human alpha-synuclein show neuronal dysfunction in the absence of aggregate formation. Mol Cell Neurosci 24:419-429.

Goldberg MS, Fleming SM, Palacino JJ, Cepeda C, Lam HA, Bhatnagar A, Meloni EG, Wu N, Ackerson LC, Klapstein GJ, Gajendiran M, Roth BL, Chesselet MF, Maidment NT, Levine MS, Shen J (2003) Parkindeficient mice exhibit nigrostriatal deficits but not loss of dopaminergic neurons. J Biol Chem 278:43628-43635.

Hofele K, Sedelis M, Auburger GW, Morgan S, Huston JP, Schwarting RK (2001) Evidence for a dissociation between MPTP toxicity and tyrosinase activity based on congenic mouse strain susceptibility. Exp Neurol 168:116-122.

Hwang DY, Ardayfio P, Kang UJ, Semina EV, Kim KS (2003) Selective loss of dopaminergic neurons in the substantia nigra of Pitx3-deficient aphakia mice. Brain Res Mol Brain Res 114:123-131.

Hwang D-Y, Fleming SM, Ardayfio P, Moran-Gates T, Kim H, Tarazi FI, Chesselet M-F, Kim K-S (2004) Pharmacological reversal of behavioral deficits of Pitx3-deficient aphakia mice: implication as an animal model of Parkinson's disease. Soc Neurosci Abstr 30:416.1.

Kolb B, Whishaw IQ (1985) Neonatal frontal lesions in hamsters impair species-typical behaviors and reduce brain weight and neocortical thickness. Behav Neurosci 99:691-706.

Langston JW, Koller WC (1991) The next frontier in Parkinson's disease: presymptomatic detection. Neurology 41:5-7.

Lees AJ (1992) When did Ray Kennedy's Parkinson's disease begin? Mov Disord 7:110-116.

Lotharius J, Brundin P (2002) Impaired dopamine storage resulting from alpha-synuclein mutations may contribute to the pathogenesis of Parkinson's disease. Hum Mol Genet 11:2395-2407.

Lotharius J, Barg S, Wiekop P, Lundberg C, Raymon HK, Brundin P (2002) Effect of mutant alpha-synuclein on dopamine homeostasis in a new human mesencephalic cell line. J Biol Chem 277:38884-38894.

Lynch CB (1980) Response to divergent selection for nesting behavior in Mus musculus. Genetics 96:757-765.

Marshall JF, Gotthelf T (1979) Sensory inattention in rats with 6-hydroxydopamine-induced degeneration of ascending dopaminergic neurons: apomorphine-induced reversal of deficits. Exp Neurol 65:398-411.

Marshall JF, Turner BH, Teitelbaum P (1971) Sensory neglect produced by lateral hypothalamic damage. Science 174:523-525.

Masliah E, Rockenstein E, Veinbergs I, Mallory M, Hashimoto M, Takeda A, Sagara Y, Sisk A, Mucke L (2000) Dopaminergic loss and inclusion body formation in alpha-synuclein mice: implications for neurodegenerative disorders. Science 287:1265-1269.

Matsuura K, Kabuto H, Makino H, Ogawa N (1997) Pole test is a useful method for evaluating the mouse movement disorder caused by striatal dopamine depletion. J Neurosci Methods 73:45-48.

Menalled LB, Chesselet MF (2002) Mouse models of Huntington's disease. Trends Pharmacol Sci 23:32-39.

Menalled LB, Sison JD, Wu Y, Olivieri M, Li XJ, Li H, Zeitlin S, Chesselet MF 
(2002) Early motor dysfunction and striosomal distribution of huntingtin microaggregates in Huntington's disease knock-in mice. J Neurosci 22:8266-8276

Menalled LB, Sison JD, Dragatsis I, Zeitlin S, Chesselet MF (2003) Time course of early motor and neuropathological anomalies in a knock-in mouse model of Huntington's disease with 140 CAG repeats. J Comp Neurol 465:11-26.

Ogawa N, Hirose Y, Ohara S, Ono T, Watanabe Y (1985) A simple quantitative bradykinesia test in MPTP-treated mice. Res Commun Chem Pathol Pharmacol 50:435-441.

Ogawa N, Mizukawa K, Hirose Y, Kajita S, Ohara S, Watanabe Y (1987) MPTP-induced parkinsonian model in mice: biochemistry, pharmacology and behavior. Eur Neurol 26[Suppl 1]:16-23.

Perez RG, Waymire JC, Lin E, Liu JJ, Guo F, Zigmond MJ (2002) A role for alpha-synuclein in the regulation of dopamine biosynthesis. J Neurosci 22:3090-3099.

Przuntek H (1992) Early diagnosis in Parkinson's disease. J Neural Transm Suppl 38:105-114.

Richfield EK, Thiruchelvam MJ, Cory-Slechta DA, Wuertzer C, Gainetdinov RR, Caron MG, Di Monte DA, Federoff HJ (2002) Behavioral and neurochemical effects of wild-type and mutated human alpha-synuclein in transgenic mice. Exp Neurol 175:35-48.

Rockenstein E, Mallory M, Hashimoto M, Song D, Shults CW, Lang I, Masliah E (2002) Differential neuropathological alterations in transgenic mice expressing alpha-synuclein from the platelet-derived growth factor and Thy-1 promoters. J Neurosci Res 68:568-578.

Rossini PM, Filippi MM, Vernieri F (1998) Neurophysiology of sensorimotor integration in Parkinson's disease. Clin Neurosci 5:121-130.

Schallert T (1988) Aging-dependent emergence of sensorimotor dysfunction in rats recovered from dopamine depletion sustained early in life. Ann NY Acad Sci 515:108-120.

Schallert T, Tillerson JL (2000) Intervention strategies for degeneration of DA neurons in parkinsonism: optimizing behavioral assessment of outcome. In: Central nervous system diseases (Emerich DF, Dean III RL, Sandberg PR, eds), pp 131-151. Totowa, NJ: Humana.

Schallert T, Whishaw IQ, Ramirez VD, Teitelbaum P (1978) Compulsive, abnormal walking caused by anticholinergics in akinetic, 6-hydroxydopamine-treated rats. Science 199:1461-1463.

Schallert T, Upchurch M, Lobaugh N, Farrar SB, Spirduso WW, Gilliam P, Vaughn D, Wilcox RE (1982) Tactile extinction: distinguishing between sensorimotor and motor asymmetries in rats with unilateral nigrostriatal damage. Pharmacol Biochem Behav 16:455-462.

Schallert T, Upchurch M, Wilcox RE, Vaughn DM (1983) Postureindependent sensorimotor analysis of inter-hemispheric receptor asymmetries in neostriatum. Pharmacol Biochem Behav 18:753-759.

Schallert T, Fleming SM, Leasure JL, Tillerson JL, Bland ST (2000) CNS plasticity and assessment of forelimb sensorimotor outcome in unilateral rat models of stroke, cortical ablation, parkinsonism and spinal cord injury. Neuropharmacology 39:777-787.

Schallert T, Woodlee MT, Fleming SM (2002) Disentangling multiple types of recovery from brain injury. In: Pharmacology of cerebral ischemia (Krieglstein J, Klumpp S, eds), pp 201-216. Stuttgart, Germany: Medpharm Scientific.

Sedelis M, Hofele K, Auburger GW, Morgan S, Huston JP, Schwarting RK (2000) MPTP susceptibility in the mouse: behavioral, neurochemical, and histological analysis of gender and strain differences. Behav Genet 30:171-182.

Sedelis M, Schwarting RK, Huston JP (2001) Behavioral phenotyping of the MPTP mouse model of Parkinson's disease. Behav Brain Res 125:109-125.

Singleton AB, Farrer M, Johnson J, Singleton A, Hague S, Kachergus J, Hulihan M, Peuralinna T, Dutra A, Nussbaum R, Lincoln S, Crawley A, Hanson M, Maraganore D, Adler C, Cookson MR, Muenter M, Baptista M, Miller D, Blancato J, et al. (2003) alpha-Synuclein locus triplication causes Parkinson's disease. Science 302:841.

Song DD, Shults CW, Sisk A, Rockenstein E, Masliah E (2004) Enhanced substantia nigra mitochondrial pathology in human alpha-synuclein transgenic mice after treatment with MPTP. Exp Neurol 186:158-172.

Szczypka MS, Kwok K, Brot MD, Marck BT, Matsumoto AM, Donahue BA, Palmiter RD (2001) Dopamine production in the caudate putamen restores feeding in dopamine-deficient mice. Neuron 30:819-828.

Tillerson JL, Miller GW (2003) Grid performance test to measure behavioral impairment in the MPTP-treated-mouse model of parkinsonism. J Neurosci Methods 123:189-200.

Tillerson JL, Cohen AD, Philhower J, Miller GW, Zigmond MJ, Schallert T (2001) Forced limb-use effects on behavioral and neurochemical effects of 6-hydroxydopamine. J Neurosci 21:4427-4435.

Tillerson JL, Caudle WM, Reveron ME, Miller GW (2002a) Detection of behavioral impairments correlated to neurochemical deficits in mice treated with moderate doses of 1-methyl-4-phenyl-1,2,3,6-tetrahydropyridine. Exp Neurol 178:80-90.

Tillerson JL, Cohen AD, Caudle WM, Zigmond MJ, Schallert T, Miller GW (2002b) Forced nonuse in unilateral parkinsonian rats exacerbates injury. J Neurosci 22:6790-6799.

Trojanowski JQ, Lee VM (2003) Parkinson's disease and related alphasynucleinopathies are brain amyloidoses. Ann NY Acad Sci 991:107-110.

Upchurch M, Schallert T (1983) A behavior analysis of the offspring of "haloperidol-sensitive" and "haloperidol-resistant" gerbils. Behav Neural Biol 39:221-228.

van der Putten H, Wiederhold KH, Probst A, Barbieri S, Mistl C, Danner S, Kauffmann S, Hofele K, Spooren WP, Ruegg MA, Lin S, Caroni P, Sommer B, Tolnay M, Bilbe G (2000) Neuropathology in mice expressing human alpha-synuclein. J Neurosci 20:6021-6029. 